\title{
PENGARUH TURNOVER INTENTION, ORGANIZATION COMMITMENT, DAN LOCUS OF CONTROL TERHADAP DYSFUCNTIONAL AUDIT BEHAVIOUR
}

\author{
Muhammad Yolly Setiawan ${ }^{1}$, Fauziah Aida Fitri ${ }^{* 2}$ \\ ${ }^{1,2}$ Program Studi Akuntansi Fakultas Ekonomi Universitas Syiah Kuala \\ e-mail: iamyolly@gmail.com ${ }^{1}$, fauziah.afitri@unsyiah.ac.id ${ }^{* 2}$
}

\section{* Corresponding Author}

\begin{abstract}
This study aims to find out and evaluate the influence of turnover intention, organization commitment and locus of control toward dysfunctional audit behavior. Based on the census method, th is research used samples of 64 respondents as auditors who work in Finance and Development Supervisory Agency (BPKP) of Aceh Representative. This study was conducted using primary data obtained through the questionnaire. The data analysis used multiple regression analysis with data processing using SPSS version 22. The result of the study shows that turnover intention does not have a significant influence on dysfunctional audit behavior. While organization commitment and locus of control have a significant influence on dysfunctional audit behavior.
\end{abstract}

Keywords: Turnover Intention, Organization Commitment, Locus of Control, Dysfunctional Audit Behavior

\section{Pendahuluan}

Perilaku merupakan karakteristik individu dalam menyesuaikan diri dengan lingkungan, yang meliputi sifat kemampuan, nilai, keterampilan, sikap dan intelegensi yang muncul dalam pola perilaku seseorang. Dapat dikatakan bahwa perilaku adalah perwujudan atas karakteristik - karakteristik individu dalam menyesuaikan diri dengan lingkungannya (Maryani dan Ludigdo, 2001). Nengsih (2004) dalam Nadirsyah dan Zuhra (2009) menyatakan bahwa perilaku auditor adalah segala bentuk tindakan yang dilakukan oleh auditor. Auditor sebagai profesi yang memberikan jasa diharuskan untuk memiliki pengetahuan dan keterampilan akuntansi serta kualitas pribadi yang memadai. Kualitas kepribadian tersebut akan terlihat dari perilaku profesionalismenya. Salah satu bentukx ' perilaku profesionalisme seorang auditor diwujudkan dalam hal menghindari perilaku disfungsional auditor (dysfunctional audit behaviour).

Dysfunctional audit behaviour adalah perilaku auditor dalam proses audit yang tidak sesuai dasar dasar prosedur audit atau menyimpang dari standar yang telah ditetapkan (Otley dan Pierce, 1996). Otley

\& Pierce (1995) menyatakan bahwa perilaku auditor terdiri atas Premature Sign-Off Audit Procedures (penghentian prosedur audit), Underreporting of Time (pelaporan tidak berdasarkan anggaran waktu), Altering or Replacing Audit Procedures (mengubah prosedur audit) merupakan beberapa perilaku yang mengarah kepada persoalan - persoalan perilaku para auditor yang akan berdampak terhadap penurunan kualitas audit sehingga cenderung menurunkan kepercayaan publik terhadap profesi akuntan dan akhirnya mematikan profesi itu sendiri.

Salah satu contoh perilaku disfungsional auditor adalah kasus Inspektur Jenderal Kemendes Sugito, yang didakwa menyuap Rochmadi Saptogiri selaku Auditor Utama Keuangan Negara III Badan Pemeriksa Keuangan (BPK), dan Ali Sadli, selaku Kepala Sub Auditorat III Auditorat Keuangan Negara. Sugito didakwa bersama-sama Kepala Bagian Tata Usaha dan Keuangan Irjen Kemendes, Jarot Budi Prabowo, diduga memberikan uang sebesar Rp 240 juta kepada dua pejabat BPK tersebut dengan tujuan agar Rochmadi memberikan opini WTP terhadap Laporan Hasil Pemeriksaan (LHP) atas Laporan Keuangan Kemendes tahun anggaran 2016. Selain itu, suap tersebut diduga untuk menutupi temuan dalam Laporan Hasil Pemeriksaan (LHP) atas Laporan Keuangan Kemendes tahun 2015 dan Semester I 2016, sebesar Rp 550 miliar (Kompas.com, 2017). Kasus ini memperkuat hasil survei transparency.org pada tahun 2016 dimana Indonesia berada diposisi 90 dari 176 
negara dengan nilai CPI (Corruption Perception Index) sebesar 37 poin (Transparency International, 2016).

Turnover intention didefinisikan sebagai kemauan dengan kesadaran dan pertimbangan untuk meninggalkan organisasi (Tett dan Meyer, 1993). Turnover intention mencerminkan keinginan individu untuk meninggalkan organisasi dan mencari pekerjaan lain (Suwandi dan Indriantoro, 1999). Penelitian Malone dan Robert (1996) ditemukan bukti bahwa ada hubungan positif yang signifikan antara turnover intention dengan dysfunctional audit behaviour karena penurunan ketakutan akan kemungkinan dijatuhkan sanksi apabila perilaku disfungsional terjadi. Hal ini menandakan bahwa auditor yang memiliki keinginan untuk meninggalkan perusahaan lebih mungkin untuk terlibat dalam perilaku disfungsional tersebut.

Organization commitment diartikan sebagai kekuatan individu dan keterlibatannya dalam organisasi tertentu (Porter et al., 1974). Menurut Porter et al. (1974) organization commitment dapat dikarakteristikkan sebagai: (1) penerimaan akan tujuan dan nilai-nilai organisasi, (2) kemauan untuk mengusahakan usaha individu kearah pencapaian tujuan, (3) keinginan yang kuat untuk mempertahankan posisi dalam organisasi.

Organization commitment menurut Donelly et al. (2003) ditentukan oleh nilai individu (lama bekerja, dan sifat pengendalian locus of control eksternal atau internal) dan organizational (desain pekerjaan, gaya kepemimpinan). Penelitian yang dilakukan oleh Maryanti (2005) menyatakan bahwa terdapat pengaruh antara organization commitment terhadap dysfunctional audit behaviour. Berbeda dengan penelitian Donelly et, al. (2003) yang menyatakan tidak terdapat pengaruh.

Locus of control adalah konsep yang dikembangkan oleh Rotter (1966) dimana dia menggolongkan individu menjadi dua kategori yaitu eksternal dan internal. Locus of control eksternal adalah individu yang percaya bahwa suatu hal dikendalikan oleh kekuatan - kekuatan luar seperti nasib, keberuntungan, dan peluang. Sedangkan locus of control internal yaitu individu yang percaya bahwa mereka memiliki kuasa atas hal - hal yang terjadi pada diri mereka. Penelitian Pujaningrum dan Sabeni (2012) menyatakan bahwa adanya pengaruh yang signifikan antara locus of control dengan tingkat penerimaan penyimpangan perilaku dalam audit. Berbeda dengan penelitian Aisyah et. al, (2014) yang menyatakan antara locus of control tidak terdapat pengaruh terhadap perilaku disfungsional audit.

Dalam penelitian ini, yang menjadi objek penelitian adalah Badan Pengawasan Keuangan dan Pembangunan (BPKP) Perwakilan Aceh. Alasan memilih BPKP Perwakilan Aceh karena provinsi Aceh merupakan salah satu provinsi yang tingkat kecurangannya tinggi di Indonesia (Fitra, 2012), dan Badan Pengawasan Keuangan dan Pembangunan menurut Peraturan Presiden (PERPRES) No. 192 Tahun 2014, Badan Pengawasan Keuangan dan Pembangunan (BPKP) merupakan aparat pengawas internal pemerintah yang kedudukannya berada di bawah dan bertanggung jawab secara langsung kepada Presiden. BPKP bertugas menyelenggarakan tugas urusan pemerintahan di bidang pengawasan keuangan negara/daerah dan pembangunan nasional.

\section{Kajian Teoritis dan Pengembangan Hipotesis Pengaruh Turnover Intention Terhadap Dysfunctional Audit Behaviour}

Dalam penelitian yang dilakukan oleh Basudewa dan Merkusiwati (2015), menunjukkan bahwa turnover intention memberikan pengaruh positif terhadap dysfunctional audit behaviour. Artinya semakin tinggi turnover intention yang dimiliki oleh seorang auditor maka akan semakin tinggi pula tingkat perilaku penyimpangan yang dilakukan oleh seorang auditor. Pernyataan ini juga didukung oleh Maryanti (2005), Donelly et al., (2003), Pujaningrum dan Sabeni (2012).

Sedangkan dalam penelitian lain, Wahyudin $e t$ al., (2011) menunjukkan bahwa turnover intention tidak mempengaruhi dysfunctional audit behaviour karena para auditor masih memiliki tingkat idealisme yang tinggi terhadap pekerjaannya sebagai seorang auditor. Dengan perbedaan hasil penelitian tersebut, peneliti ingin meneliti kembali tentang pengaruh turnover intention terhadap dysfunctional audit behavior.

\section{Pengaruh Organization Commitment \\ Terhadap Dysfunctional Audit Behaviour}

Individu dengan komitmen organisasi rendah mungkin tertarik dalam pursuing self-interest dibandingkan dengan kepentingan organisasi (Donelly 
et al., 2003). Individu tersebut cenderung menunjukkan penerimaannya atas perilaku audit disfungsional untuk pencapaian pribadi. Donelly et al. (2003) telah melakukan penelitian tentang hubungan organization commitment dengan dysfunctional audit behaviour yang menunjukkan hasil negatif signifikan antara kedua variabel tersebut, sedangkan hasil penelitian Maryanti (2005), menyatakan bahwa keduanya berhubungan positif signifikan. Dengan perbedaan ini peneliti ingin meneliti kembali tentang pengaruh organization commitment terhadap dysfunctional audit behaviour.

\section{Pengaruh Locus of Control Terhadap Dysfunctional Audit Behaviour}

Hartati (2012) menyatakan bahwa individu yang memiliki locus of control internal cenderung tidak menerima perilaku disfungsional atas prosedur audit. Sebaliknya individu yang memiliki locus of control eksternal biasanya memiliki kedudukan dibawah individu yang memiliki locus of control internal. Hal ini dikarenakan individu dengan locus of control eksternal kurang percaya akan kemampuan dirinya sendiri dalam melakukan suatu pekerjaan dan tidak bisa menentukan nasib baiknya sendiri. Penelitian Wahyudin et, al., (2011), Maryanti (2005) dan Donelly et al., (2003), menunjukkan bahwa locus of control berpengaruh positif terhadap penerimaan dysfunctional audit behaviour. Sehingga peneliti ingin menguji hipotesa ini.

\section{Hipotesis}

Berdasarkan gambar 2.1, maka dapat dirumuskan hipotesis sebagai berikut:

H1: Turnover intention, Organization Commitment, dan Locus of Control secara simultan berpengaruh terhadap Dysfunctional Audit Behaviour.

H2: Turnover Intention secara parsial berpengaruh terhadap Dysfunctional Audit Behaviour.

H3: Organization Commitment secara parsial berpengaruh terhadap Dysfunctional Audit Behaviour.

H4: Locus of Control secara parsial berpengaruh terhadap Dysfunctional Audit Behaviour.

\section{Metode Penelitian Desain Penelitian}

Penelitian ini bertujuan untuk menguji hipotesis. Jenis investigasi pada penelitian ini menggunakan jenis penelitian studi kausalitas (causality study) dimana tingkat intervensi dalam penelitian ini adalah intervensi minimal. Situasi penelitian ini adalah tidak diatur. Unit analisis didalam penelitian ini adalah unit analisis individual, yaitu para auditor yang bekerja di BPKP Perwakilan Aceh dan data yang dikumpulkan yaitu berupa data primer dalam bentuk kuesioner. Horizon waktu yang digunakan pada penelitian ini bersifat cross-sectional.

\section{Populasi dan Sampel}

Populasi pada penelitian ini adalah seluruh auditor yang bekerja pada Badan Pengawasan Keuangan dan Pembangunan (BPKP) Perwakilan Aceh. Teknik pengambilan sampel menggunakan teknik sensus. Sensus adalah teknik penentuan sampel apabila semua anggota populasi digunakan sebagai sampel (Sugiyono, 2013:85). Metode sensus dipilih karena elemen populasi sasaran yang diteliti jumlahnya sedikit.

\section{Sumber dan Teknik Pengumpulan Data}

Penelitian ini termasuk dalam penelitian kuantitatif dengan menggunakan data primer berupa kuesioner sebagai sumber data. Kuesioner terdiri atas pernyataan-pernyataan yang mewakili kriteria yang menjadi variabel bebas dan terikat dalam penelitian ini. Data primer yang diambil dalam penelitian ini dengan mengajukan pernyataan tertulis melalui kuesioner dengan responden auditor yang bekerja pada kantor BPKP Perwakilan Aceh

\section{Operasionalisasi Variabel Variabel Dependen}

Variabel dependen merupakan variabel terikat dan dipengaruhi oleh variabel independen. Variabel dependen dalam penelitian ini adalah Dysfunctional Audit Behaviour (Penyimpangan Perilaku dalam Audit). Dysfunctional audit behaviour adalah perilaku auditor dalam proses audit yang tidak sesuai dengan program audit yang telah ditetapkan atau menyimpang dari standar yang telah ditetapkan (Otley dan Pierce, 
1996). Variabel ini terdiri dari 3 tipe perilaku, yaitu Altering/replacing of audit procedure, Premature sign off, dan Underreporting of audit time. Variabel ini diukur menggunakan 12 indikator pertanyaan yang dikembangkan oleh Donelly et.al (2003).

\section{Variabel Independen \\ Turnover Intention}

Turnover intention didefinisikan sebagai kemauan dengan kesadaran dan pertimbangan untuk meninggalkan organisasi (Tett dan Meyer, 1993). Variabel turnover intention diukur dengan 4 indikator yang dikembangkan oleh Maslach \& Jackson (1981). Skala pengukuran yang digunakan dalam penelitian ini adalah skala interval, dengan skala likert 5 poin.

\section{Organization Commitment}

Organization Commitment didefinisikan sebagai kekuatan individu dan keterlibatannya dalam organisasi tertentu (Porter et al., 1974). Ada 9 indikator yang dikembangkan oleh Mowday (1979) yang digunakan untuk menilai variabel ini. Skala pengukuran yang digunakan dalam penelitian ini adalah skala interval, dengan skala likert 5 poin.

\section{Locus of Control}

Rotter (1966) menjelaskan bahwa Locus of Control adalah cara pandang atau persepsi seseorang terhadap suatu peristiwa apakah dia dapat atau tidak mengendalikan peristiwa yang terjadi padanya, yaitu tingkatan dimana seseorang menerima tanggung jawab personal terhadap apa yang terjadi pada diri mereka. Variabel ini dinilai dengan menggunakan 13 pertanyaan Spector (1988) yang telah di kembangkan oleh Febrina (2012). Skala pengukuran yang digunakan dalam penelitian ini adalah skala interval, dengan skala likert 5 poin.

\section{Hasil dan Pembahasan \\ Deskripsi Objek Penelitian}

Data dalam penelitian ini merupakan data primer berupa kuesioner. Kuesioner didistribusikan kepada 64 auditor BPKP Perwakilan Aceh yang menjadi sampel penelitian, mengingat jumlah populasi tidak terlalu besar maka peneliti mengambil seluruh populasi sebagai sampel atau biasa disebut teknik sensus. Kuesioner dibagikan kepada staf bagian pemeriksa (auditor) sebagai pihak yang terlibat langsung dalam pemeriksaan laporan keuangan. Proses pendistribusian hingga pengumpulan data dilakukan selama satu bulan pada tanggal 21 Maret 2018 sampai dengan tanggal 20 April 2018.

Responden dalam penelitian ini memiliki karakterisktik yang berbeda. Berdasarkan hasil penyebaran kuesioner kepada 64 responden, dapat dijelaskan dengan responden pria dalam penelitian ini berjumlah 39 atau $60,9 \%$ sedangkan responden wanita berjumlah $39,1 \%$.

Untuk karakteristik berdasarkan usia dapat dijelaskan bahwa responden yang berusia 21-30 tahun adalah sebanyak 19 orang atau sebesar $29,7 \%$, untuk usia 31-40 tahun adalah sejumlah 22 orang atau sebesar 34,4\%, untuk usia 41-50 tahun adalah sejumlah 12 orang atau sebesar $18,8 \%$ dan yang berusia lebih dari 50 tahun adalah sejumlah 11 orang atau sebesar $17,2 \%$. Dalam penelitian ini, dari 64 responden jumlah terbanyak adalah yang berusia 31- 40 tahun. Sedangkan untuk karakteristik berdasarkan jenjang pendidikan, dapat dijelaskan bahwa 3 orang responden yang berjenjang pendidikan diploma III atau sebesar 4,7\%. Untuk jenjang pendidikan strata I adalah sejumlah 53 orang atau sebesar $82,8 \%$, dan untuk jenjang pendidikan strata II berjumlah 8 orang atau sebesar $12,5 \%$. Tidak ada responden yang berjenjang pendidikan strata III. Data ini menunjukkan

\begin{tabular}{|l|l|l|}
\hline Koefisien Regresi $(\mathrm{R})$ & $=$ &, $450^{\mathrm{a}}$ \\
\hline Koefisien Determinasi $\left(\mathrm{R}^{2}\right)$ & $=$ & 0,202 \\
\hline Adjusted $\left(\mathrm{R}^{2}\right)$ & $=$ & 0,162 \\
\hline
\end{tabular}

Hasil output SPSS (coefficients), dapat diperoleh persamaan regresi berganda (multiple regression) sebagai berikut:bahwa responden dengan jenjang pendidikan strata I merupakan responden terbanyak dalam penelitian ini.

$$
Y=5,916-0,035 X_{1}-0,370 X_{2}-0,407 X_{3}+e
$$

Selanjutnya untuk karakterisitik berdasarkan masa kerja, dapat dijelaskan bahwa dari 64 jumlah responden, untuk responden yang bekerja selama $<1$ tahun adalah sejumlah 1 orang atau sebesar $1,6 \%$, 
untuk yang bekerja selama 1-3 tahun adalah sejumlah 2 orang atau sebesar $3,1 \%$, untuk masa bekerja 4-5 tahun adalah sejumlah 16 orang atau $25,0 \%$ dan untuk yang bekerja selama $>5$ tahun adalah sejumlah 45 orang atau sebesar 70,3\%. Data ini menunjukkan bahwa responden dengan lama bekerja $>5$ tahun merupakan responden terbanyak dalam penelitian ini.

Penelitian yang akan dilaksanakan sebelumnya terlebih dahulu dilakukan uji kualitas data yaitu uji validitasd dan uji reliabilitas, setelah itu dilakukan analisis data menggunakan uji asumsi klasik yaitu uji normalitas, uji multikolonearitas dan uji heteroskedastisitas. Kemudian, dilakukan uji hipotesis yaitu uji $\mathrm{t}$ dan juga analisis regresi berganda dengan melihat nilai signifikan pada $0,05(5 \%)$.

Berdasarkan hasil uji kualitas data, data penelitian dikatakan valid dan reliabel sehingga dapat dilanjutkan sebagai bahan penelitian. Hasil dari data penelitian menunjukkan bahwa data penelitian normal dan bebas dari multikolonearitas maupun heteroskedastisitas.

\section{Hasil Pengujian Regresi Linier Berganda}

Dari persamaan regresi dapat diketahui hasil penelitian dari masing-masing koefisien yaitu untuk konstanta $(a=8,580)$ artinya jika faktor turnover intention (X1), organization commitment (X2) dan locus of control di anggap konstan maka besarnya dysfunctional audit behavior adalah sebesar 5,916. Sedangkan koefisien turnover intention (X1) sebesar $-0,035$, organization commitment sebesar $-0,370$, dan locus of control (X3) sebesar $-0,407$

\begin{tabular}{|c|c|c|c|c|c|c|c|}
\hline & \multicolumn{2}{|c|}{$\begin{array}{c}\text { Unstandardized } \\
\text { Coefficients }\end{array}$} & \multirow{2}{*}{\begin{tabular}{|c}
$\begin{array}{l}\text { Standardized } \\
\text { Coefficients }\end{array}$ \\
Beta
\end{tabular}} & \multicolumn{2}{|c|}{ Simultan } & \multicolumn{2}{|c|}{ Parsial } \\
\hline & B & $\begin{array}{l}\text { Std. } \\
\text { Error }\end{array}$ & & $\mathbf{F}$ & Sig. & $\mathbf{T}$ & Sig. \\
\hline Konstanta & 5,916 & ,874 & & \multirow{4}{*}{5,074} & \multirow{4}{*}{, $003^{\mathrm{a}}$} & 6,771 &, 000 \\
\hline $\begin{array}{l}\text { Turnover } \\
\text { Intention }\end{array}$ &,- 035 & ,108 &, 042 & & &,- 323 &, 748 \\
\hline $\begin{array}{l}\text { Organization } \\
\text { Commitment }\end{array}$ &,- 370 &, 160 & ,316 & & & $-2,319$ &, 024 \\
\hline $\begin{array}{l}\text { Locus of } \\
\text { Control }\end{array}$ &,- 407 & ,201 &, 250 & & & $-2,029$ &, 047 \\
\hline
\end{tabular}

\section{Pengujian Hipotesis}

Pengaruh Turnover Intention, Organization Commitment dan Locus of Control terhadap Dysfunctional Audit Behaviour

Berdasarkan hasil pengujian statistik $\mathrm{F}$ secara simultan bahwa turnover intention, organization commitment dan locus of control berpengaruh terhadap dysfunctional audit behaviour di BPKP Perwakilan Aceh. Hal ini sesuai dengan hipotesis yang dibuat sebelumnya, yaitu turnover intention, organization commitment dan locus of control berpengaruh secara bersama-sama (simultan) terhadap dysfunctional audit behaviour. Ketiga variabel tersebut dapat mempengaruhi dysfunctional audit behaviour para auditor BPKP Perwakilan Aceh.

\section{Pengaruh Turnover Intention terhadap Dysfunctional Audit Behaviour}

Berdasarkan hasil regresi linear berganda, nilai koefisien regresi menunjukan bahwa turnover intention tidak berpengaruh terhadap dysfunctional audit behaviour para auditor BPKP Perwakilan Aceh. Hal ini menolak hipotesis yang telah dibuat, yaitu turnover intention berpengaruh terhadap dysfunctional audit behaviour. Hal ini menunjukkan bahwa kenyataan dilapangan tidak terdapat pengaruh antara auditor yang memiliki turnover intention dengan tingkat penerimaan auditor terhadap dysfunctional audit behaviour. Hal lain yang menyebabkan turnover intention tidak berpengaruh terhadap dysfunctional audit behaviour adalah karena para auditor memiliki tingkat idealisme yang tinggi terhadap pekerjaannya sebagai seorang auditor, sehingga auditor akan melaksanakan tugas audit yang menjadi tanggungjawabnya dengan sebaik - baik mungkin dan juga sesuai dengan prosedur, aturan dan kebijakan yang telah berlaku. Hasil penelitian ini memberikan bukti empiris bahwa auditor yang memiliki turnover intention yang rendah maka auditor tersebut tidak menunjukkan kecenderungan untuk melakukan dysfunctional audit behaviour, sebagaimana yang dihipotesiskan.

Hasil penelitian ini tidak konsisten dengan hasil penelitian yang dilakukan oleh Basudewa dan Merkusiwati (2015) yang menyatakan bahwa turnover intention berpengaruh positif dan signifikan terhadap dysfunctional audit behaviour. Malone dan Roberts (2003) yang terdapat dalam Pujaningrum 
(2012) menjelaskan bahwa auditor yang memiliki turnover intention yang tinggi lebih mungkin terlibat dalam dysfunctional audit behaviour, karena penurunan rasa takut dari kondisi yang terjadi bila hal tersebut terdeteksi.

\section{Pengaruh Organization Commitment terhadap Dysfunctional Audit Behaviour}

Berdasarkan hasil regresi linear berganda, nilai koefisien regresi menunjukan bahwa organization commitment berpengaruh terhadap dysfucntional audit behaviour para auditor di BPKP Perwakilan Aceh. Hal ini sesuai dengan hipotesis yang telah dibuat, yaitu Organization Commitment berpengaruh terhadap dysfunctional audit behaviour. Hasil penelitian ini menunjukkan bahwa semakin tinggi organization commitment yang dimiliki oleh seorang auditor maka akan semakin rendah kemungkinan terjadinya dysfunctional audit behaviour yang dilakukan oleh auditor tersebut. Ketika seorang auditor yang berkomitmen tinggi terhadap organisasinya sedang melakukan audit mendapatkan tekanan dari pihak yang sedang diperiksa yang memiliki kepentingan lain, ia akan menolak tekanan tersebut karena ingin menjaga nama baik dan integritas organisasinya. Sedangkan auditor yang berkomitmen rendah terhadap organisasinya akan lebih mengutamakan kepentingan pribadinya, sehingga ketika dia diminta untuk memanipulasi laporan keuangan dengan imbalan yang besar ia akan menerima permintaan tersebut. Dengan demikian auditor tersebut telah melakukan dysfunctional audit behaviour.

Hasil penelitian ini konsisten dengan penelitian yang dilakukan Basudewa dan Merkusiwati (2015), dan penelitian Pujaningrum dan Sabeni (2012). Selain itu, penelitian Paino et. al. (2011) menjelaskan bahwa organizational commitment berpengaruh negatif terhadap dysfunctional audit behavior. Dijelaskan bahwa tingkat tinggi rendahnya organization commitment seorang auditor akan dikaitkan dengan dysfunctional audit behaviour, hal ini dilakukan dengan tujuan untuk tetap mempertahankan organisasi tempat mereka bekerja. Organization commitment menurut Donelly et al. (2003) ditentukan oleh nilai pribadi (usia lama kerja, perangai atau sifat seperti pengaruh positif atau negatif, sifat pengendalian locus of control eksternal atau internal) dan organizational (desain pekerjaan, gaya kepemimpinan pengawas).

\section{Pengaruh Locus of erhadap Dysfunctional Audit Behaviour}

Berdasarkan hasil regresi linear berganda, nilai koefisien regresi menunjukan bahwa locus of control berpengaruh terhadap dysfucntional audit behaviour para auditor di BPKP Perwakilan Aceh. Hal ini sesuai dengan hipotesis yang telah dibuat, yaitu locus of control berpengaruh terhadap dysfunctional audit behaviour. Hasil penelitian ini menunjukkan bahwa tinggi rendahnya locus of control yang dimiliki oleh seorang auditor akan mempengaruhi penerimaannya atas dysfunctional audit behaviour. Hal ini dapat memberikan gambaran bahwa instansi BPKP Perwakilan Aceh memiliki lingkungan kerja yang baik dan menerapakan nilai nilai dasar dengan sungguh - sungguh sehingga memberikan motivasi yang baik bagi para auditor untuk bekerja lebih baik. Hasil penelitian ini juga menunjukkan bahwa kenyataan dilapangan terdapat pengaruh antara locus of control auditor dengan tingkat penerimaan auditor terhadap dysfunctional audit behaviour. Hasil penelitian menunjukkan kesesuaian dengan penelitian Basudewa dan Merkusiwati (2015) dan Hartati (2012), dimana pada saat individu merasa bahwa kemampuannya tidak sesuai dengan tuntutan pekerjaan, maka individu tersebut cenderung melakukan perilaku disfungsional untuk mempertahankan posisinya.

\section{Kesimpulan, Keterbatasan dan Saran Kesimpulan}

Berdasarkan hasil penelitian dan pembahasan yang diperoleh, maka dapat disimpulkan bahwa:

1) Turnover intention, organization commitment, dan locus of control secara simultan berpengaruh terhadap dysfunctional audit behaviour pada auditor BPKP Perwakilan Aceh. Hal ini berarti sesuai dengan hipotesis yang dibuat sebelumnya.

2) Turnover intention tidak berpengaruh terhadap dysfunctional audit behaviour pada auditor BPKP Perwakilan Aceh. Berdasarkan hasil penelitian, maka penelitian ini menolak hipotesis yang telah dibuat sebelumnya. 
3) Organization commitment berpengaruh terhadap dysfunctional audit behaviour pada auditor BPKP Perwakilan Aceh. Hal ini menunjukkan kesesuaian dengan hipotesis yang dibuat sebelumnya.

4) Locus of control berpengaruh terhadap dysfucntional audit behaviour pada auditor BPKP Perwakilan Aceh. Hal ini menunjukkan bahwa hipotesis yang dibuat sebelumnya diterima.

\section{Keterbatasan}

Penelitian ini mempunyai beberapa kelemahan yang membatasi kesempurnaannya. Oleh karena itu, keterbatasan dalam penelitian ini perlu diperhatikan agar peneliti selanjutnya memperoleh hasil yang lebih baik dimasa yang akan datang. Adapun keterbatasan penelitian ini adalah sebagai berikut:

1) Penelitian ini menggunakan data primer yang berupa kuesioner. Salah satu dari kelemahan pengambilan data dari kuesioner adalah responden tidak dapat memberikan keterangan lebih detail selain dari pernyataan yang ada di dalam kuesioner dan tidak menutup kemungkinan bahwa persepsi responden berbeda dengan keadaan yang sesungguhnya.

2) Penelitian ini hanya menggunakan tiga variabel independen yaitu turnover intention, organization commitment dan locus of control untuk melihat pengaruh dysfunctional audit behaviour. Beberapa variabel lain yang mungkin mempengaruhi dysfunctional audit behaviour tidak diikut sertakan dalam penelitian ini.

\section{Saran}

Berdasarkan hasil analisis pembahasan serta beberapa kesimpulan dan keterbatasan pada penelitian ini, maka peneliti memberikan beberapa saran :

1) Agar penelitian dapat dikatakan lebih representatif, maka diharapkan penelitian selanjutnya dapat memperbanyak jumlah responden dan memperbesar ruang lingkup penelitian agar penelitian kedepan memiliki cakupan yang lebih luas dan menghasilkan hasil penelitian yang lebih baik.

2) Penelitian selanjutnya disarankan agar menambah beberapa variabel independen lain yang dapat mempengaruhi dysfunctional audit behaviour, sehingga dapat diketahui bahwa dysfunctional audit behaviour juga dipengaruhi oleh variabel-variabel lain selain yang telah digunakan dalam penelitian ini.

3) Pada penelitian ini peneliti menggunakan kuesioner untuk mendapatkan informasi data penelitian, jika memungkinkan penelitian selanjutnya dapat melakukan wawancara langsung dengan para auditor agar mendapat data yang lebih akurat.

\section{Daftar Pustaka}

Aisyah, Ramadhani N., Sukirman, \& Dhini Suryandari. (2014). Faktor-Faktor Yang Mempengaruhi Perilaku Disfungsional Audit: Penerimaan Auditor BPK RI Jateng. Accounting Analysis Journal.

Basudewa, Dewa G. A., \& Lely A. M. (2015). Pengaruh Locus Of Control, Komitmen Organisasi, Kinerja Auditor, dan Turnover Intention Pada Perilaku Menyimpang Dalam Audit. E-Jurnal Akuntansi Universitas Udayana.

Donnelly, David P., Jeffrey J. Quirin., \& David O'Bryan. (2003). Attitudes Toward Dysfunctional Audit Behavior: The Effects Of Locus Of Control, Organizational Commitment, And Position. The Journal of Applied Business research, Volume 19 Number, pp. $75-108$.

Fitra. (2012). Ini Dia Provinsi Terkorup di Indonesia Versi Fitra. Melalui (http://news.detik.com). Diakses pada tanggal 12 November 2016

Hartati, Nian Lucky. (2012). Pengaruh Karakteristik Internal Dan Eksternal Auditor Terhadap Penerimaan Perilaku Disfungsional Atas Prosedur Audit. Accounting Analysis Journal. Semarang: Universitas Negeri Semarang.

Malone, C. F., \& R. W. Roberts. (1996). Factor Associated with the Incidence of Reduced Audit Quality Behaviors. Auditing: A Journal of Practice and Theory. Vol. 15, no. 2. pp 49-6

Maryani, T., \& Ludigdo, U. (2001). Survey atas Faktor-faktor yang Mempengaruhi Sikap dan 
Perilaku Etis Akuntan. Jurnal TEMA 2 (1): 4962.

Maslach, C., \& Jackson, S. E. (1981). The measurement of experienced burnout. Journal of Occupational Behavior, 2, 99-113.

Mowday, R. T., Steers, R. M., \& Porter, R. M. (1979). The measurement of organizational commitment. Journal of Vocational Behaviour, 14, 224 - 227.

Nadirsyah., \& Zuhra, I. M. (2009). Locus of Control, Time Budget Pressure, dan Penyimpangan Perilaku Dalam Audit”. Jurnal Telaah dan Riset Akuntansi. 2(2): 104 - 116. Universitas Syiah Kuala. Aceh.

Otley, D. T., \& Pierce, B. J. (1995). The control problem in public accounting firms: An empirical study of the impact of leadership style. Accounting, Organizations and Society, 20(5), 405-420.

. (1996). "The Operation Of Control Systems in Large Audit Firms." Auditing: A Journal of Practice and Theory 15 (2).

Paino, Halil., Ismail, Zubaidah., \& Smith, Malcolm. (2014). Modelling Dysfunctional Behaviour: Individual Factors and Ethical Financial Decision. Procedia - Social and Behavioral Sciences 145 page $116-128$

Porter, L. W., Steers, R. M., Mowday, R. T., \& Boulian, P. V. (1974). Organizational commitment, job satisfaction, and turnover among psychiatric technicians. Journal of Applied Psychology, 59(5), 603-609.

Pujaningrum, I., \& Sabeni, Arifin. (2012). Analisis Faktor-Faktor yang Mempengaruhi Tingkat Penerimaan Auditor atas Penyimpangan Perilaku dalam Audit: Studi Empiris Pada Kantor Akuntan Publik di Semarang. Diponegoro Journal of Accounting. Volume 1. No. 1.

Republik Indonesia. (2014). Peraturan Presiden No. 192 Tahun 2014 Tentang Badan Pengawasan Keuangan dan Pembangunan. Jakarta.
Rotter, J. B. (1966). Generalized Expectancies for Internal versus External Control of Reinforcement. Psychological Monographs, Vol. 80, whole No. 609

Sugiyono. (2013). Statistik Untuk Penelitian. Bandung: Alfabeta.

Suwandi \& N. Indriantoro. (1999). Pengujian Model Turnover Pasewark dan Strawser: Studi Empiris pada Lingkungan Akuntan Publik. Jurnal Riset Akuntansi Indonesia, Vol. 2 No. 2, 173-195.

Tett, R. P., \& Meyer, J. P. (1993). Job Satisfaction, Organizational Commitment, Turnover Intention, and Turnover: Path Analyses Based on Meta- Analytic Findings. Personnel Psychology, 46 (2), 259-2.

Wahyudin, Agus., Anisykurlillah, Indah \& Dwi Harini. (2011). Analisis Dysfunctional Audit Behavior: Sebuah Pendekatan Karakteristik Personal Auditor. Semarang: Jurnal Dinamika Akuntansi. 